\title{
Knowledge and Attitude of Parents from Fujairah, UAE about Emergency Management of Dental Trauma- A Questionnaire based Study
}

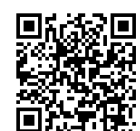

\author{
Ergieg SM${ }^{1 *}$, Rashwan $\mathbf{O A}^{2}$ and Al Shammar $\mathbf{M A}^{1}$
}

${ }^{1}$ Department of Pediatric Dentistry, Ajman University, UAE

${ }^{2}$ Department of Mathematics \&Science, Ajman University, UAE

Submission: February 08, 2019; Published: March 01, 2019

*Corresponding author: Ergieg SM, Department of Pediatric Dentistry, Ajman University, Fujairah, UAE

\begin{abstract}
Traumatic dental injuries frequently occur in the society and may occur mostly at home environment. It occurs frequently in children and adolescents. Prompt and appropriate emergency management is important for the best long-term prognosis of teeth affected. The knowledge of parents regarding the immediately steps to be taken after dental trauma is exceedingly crucial for success of the treatment.
\end{abstract}

Aim: The study was carried out to evaluate the knowledge and attitude of parents from Fujairah, UAE about emergency management of dental trauma.

Materials \& Methods: A hundred parents of school going children from Fujairah, UAE. Each participant given a questionnaire and was asked to answer the questions about the knowledge of emergency management of dental trauma. The questionnaire comprised of two parts: First part contained the general demographic data and the second part includes closed questions, which assessed the knowledge and attitude of participant about the emergency management of traumatized permanent tooth.

Result: The result of the study showed more than half (69\%) of the participants were female. $78 \%$ were claimed to identify the difference between milk and permanent teeth. $42 \%$ claimed to know how manage dental trauma, through community dental health and other sources. $81 \%$ stated to go to hospital.76\% were unsatisfied with their level of knowledge. Chi-square test shows that there is a significant association between the level of education and the source of knowledge.

Keywords: Dental trauma; Permanent Tooth; Parents \& knowledge

\section{Introduction}

Dental injuries are one of the most commonly encountered dental emergencies. Traumatic dental injuries pose significant consequences to the health of the child, not only functionally, but also psychologically and socially [1]. These consequences also have significant impact on parents, who are generally concerned with esthetic and economic aspects of this problem [2]. The prognosis of some dental injuries depends largely on parents' knowledge of correct and prompt emergency measures [3]. Traumatic injuries can, thus, have a significant impact on a child's quality of life. A high percentage of children with dental trauma present late for treatment, possibly because of lack of awareness and knowledge among related adults, resulting in unfavorable long-term prognosis. Parents, especially mothers play an important role in their children' life, as they are the primary source of information allowing importing their knowledge. Forty-one percent of dental injuries occur at home. Mothers therefore should play an important role in taking appropriate decision [4]. Increased overjet, environmental determinants and human behavior were found to increase the risk for traumatic dental injuries [3]. Statistics from many countries show that one third of preschool children suffer from traumatic dental injuries involving primary dentition and one-fourth permanent dentition. Between $71 \%$ and $92 \%$ of all injuries, sustained in a lifetime occur before the age of 19. They occur at home followed by school and public places [5]. $50 \%$ of school children have sustained traumatic injuries prior to graduation [4]. In Asia and Africa, the prevalence of TDI to anterior teeth among adolescents ranges from $4 \%$ to $35 \%$ and from $15 \%$ to 21\%, respectively. In America and Europe, the prevalence varied from $15 \%$ to $23 \%$ and $23 \%$ to $35 \%$, respectively [6].

Appropriate emergency management of dental trauma carried out by medical professional could drastically improve the prognosis of traumatized teeth [7]. The emergency care following 


\section{Advances in Dentistry \& Oral Health}

traumatic injuries is essential for good prognosis of the injuries. Parent are often responsible for the health of their children. Hence, they should have the required knowledge about emergency management of traumatic dental injuries.

\section{Aims and Objectives}

The aim of this study was to assess the awareness and parents' knowledge about emergency management of traumatic dental injuries.

\section{Materials and Methods}

A sample of hundred parents of school going children accompanied their children, aged between 6 and 12 years, for receiving dental care in the Department of Pedodontics, Dental Clinic, Ajman University- Fujairah Campus between February and May 2017, were participated in this study. The participants were asked to complete, a 13-stemmed multiple-choice questionnaire designed in Arabic and English, which was a modified form of the questionnaire used by Raphael et al. [8]. The questionnaire was comprised of two parts: First part contained the general demographic data and the second part includes closed questions, which assessed the knowledge, attitude, and previous experience of the participant about the emergency management of traumatized permanent tooth.

The questionnaire explained to all participants before its distribution. Collection of the completed questionnaire was done immediately, after has been completed by parents. A written informed consent form according to the ethical guidelines was subsequently, obtained from the participants. Ethical approval obtained from, REC, Ref. GDF-2017/18-06-S (Table 1).

Table 1: Sample distribution by gender.

\begin{tabular}{|c|c|c|}
\hline Gender & Number(n) & Percentage $\%$ \\
\hline Female & 69 & $69 \%$ \\
\hline Male & 31 & $31 \%$ \\
\hline Total & 100 & $100 \%$ \\
\hline
\end{tabular}

\section{Data Analysis}

The data obtained were processed and statistically analyzed, using Statistical Package for the Social science (SPSS) software. Frequency analysis related to participants' gender and educational levels was performed. Chi-square test was used to test the level of significance.

\section{Results}

The result of the study showed more than half $(69 \%)$ of the participants were female. 78\%pf participants claimed to identify the difference between milk and permanent teeth. $42 \%$ claimed to know how manage dental trauma, through community dental health and other sources. $81 \%$ said that they would consult hospital when the accident occurs and $76 \%$ were unsatisfied with their level of knowledge.

The study sample has three independent variables: Gender, Age, and Level of education. The frequency of each category in every variable is shown in Table 2 . Chi-square result is given in Table 3.

Table 2: Frequency Distribution (education, age group and gender).

\begin{tabular}{|c|c|c|c|c|}
\hline & Frequency & Percent & Valid \% & Cumulative \% \\
\hline \multicolumn{5}{|c|}{ Education } \\
\hline Do not complete school. & 11 & 11 & 11 & 11 \\
\hline Complete school. & 41 & 41 & 41 & 52 \\
\hline Graduate college & 43 & 43 & 43 & 95 \\
\hline Post- graduate. & 5 & 5 & 5 & 100 \\
\hline Total. & 100 & 100 & 100 & 100 \\
\hline \multicolumn{5}{|c|}{ Age Group } \\
\hline Below 25 yrs. & 14 & 14 & 14 & 14 \\
\hline Between 25 -35yrs & 47 & 47 & 47 & 61 \\
\hline Above 35 yrs. & 39 & 39 & 39 & 100 \\
\hline Total. & 100 & 100 & 100 & 100 \\
\hline \multicolumn{5}{|c|}{ Gender } \\
\hline Male. & 69 & 69 & 69 & 69 \\
\hline Female & 31 & 31 & 31 & 100 \\
\hline Total & 100 & 100 & 100 & 100 \\
\hline
\end{tabular}

Table 3: Chi-square test.

\begin{tabular}{|c|c|c|c|c|}
\hline & Knowledge & Source of Knowledge & Attitude & Prevention \\
\hline Gender & 0.506 & 0.352 & 0.779 & 0.216 \\
\hline Age & 0.847 & 0.834 & 0.652 & 0.216 \\
\hline Level of Education & 0.113 & 0.033 & 0.09 & 0.005 \\
\hline
\end{tabular}


Chi-square test (Table 3) shows that there is a significant association between the level of education and the source of knowledge about dental trauma (sign 0.033) and trauma prevention (sign 0.005). Nevertheless, there is no significant association between educational Level and attitude (sign 0.09) and between educational level and knowledge about trauma (sign 0.113).

Regarding gender, no significant association between gender and source of knowledge (sign 0.352), prevention (sign 0.216), attitude (sign 0.779), and knowledge (sign 0.506), neither between age groups and source of knowledge (sign 0.834), prevention (sign 0.216), attitude (sign 0.652), and knowledge about Trauma (sign 0.847).

\section{Discussion}

Traumatic injuries not only, pose a health risk worldwide, but are also regarded as a serious social problem. An important category of these injuries, dental trauma, which accounts, for a major part of health problem in children and adolescents. Demographic evaluation indicates a higher prevalence of traumatic dental injuries to anterior teeth in males than females in male [9]. Falling fight, sport, accidents, and hitting items or people are among common etiologic factors. Home setting, schools, and streets are places with the highest frequency of dental traumatic injuries [10]. 69\% of participants were female parent (mother). This finding is like those of Divya [1] revealed that $70.6 \%$ of the participants were female. $43 \%$ of participants have graduated from college/ universities. This figure is higher than $20.4 \%$ reported by [11]. Only $24 \%$ of the parents who participated in this study were satisfied with their level of knowledge in managing dental trauma. This result was lower than $51.3 \%$ reported by [3]. 35\% of parents stated that their children suffer dental trauma. This figure agrees with that reported by Kinoshita-Kawano [12].

The information the parent gave about emergency management of dental trauma came from different sources school programs, TV, community dental health and other sources. It has been found that $22 \%$ of parents claimed not to supervise their children during playing activities. This figure is higher than that given by Mitakshara Nirwan [13] regarding the teacher where only $11 \%$ of them did not supervise the children. This difference may be related to the fact that parents are from different education levels, thoughts, beliefs, and ages. On the other hand, the teachers are well educated, and their duty requires them to take care of children and supervise them. The present study found parents have a low level of knowledge regarding the emergency management of traumatized tooth. This can be explained by the fact that most parents had not received any prior information about the management of traumatic dental injuries.

Chi-square test shows that there was a significant association between the level of education and the source of knowledge and trauma prevention. It was observed that parents with higher educational background have shown much positive attitude toward emergency management of traumatized permanent tooth.
Female parents exhibiting higher knowledge level. This may be because $69 \%$ of the participants were females and $70 \%$ of them graduated from college. Nevertheless, in general there was no significant association between the level of educational and trauma awareness and knowledge.

There association between gender and source of knowledge, trauma prevention, attitude, and knowledge about trauma was not statistically significant. Neither was there any significance association between age groups and source of knowledge, trauma prevention, attitude, and knowledge of trauma management. Despite absence of a significant relation between parent's level of education and dental trauma management, there was a sign that $76 \%$ of them were not satisfied with their knowledge and therefore still require further learn about emergency management of dental trauma injuries in children.

\section{Conclusion}

With limitation of this study, it was concluded that regardless of educational background parental awareness concerning measures in emergency management of dental trauma was markedly inadequate. This study revealed the lack of knowledge among parents in Emirate of Fujairah about dealing with emergency management of traumatic dental injury, which c have high impact on the long-run term prognosis of treatments. There is a need to improve the level of education of parents about dental trauma. The relationship between educational level and parent/ child interaction, allows parents with higher education to use more effective strategies when dealing with childrearing. A community based oral health program will be of great help in raising parents' awareness about their children's oral health. This study will help providing a base line data for local and state authorities to establish educational program focusing on a prompt management of dental trauma targeting parents, maternity centers and schoolteachers.

\section{References}

1. Chandukutty D, Peedikayil FC, Premkumar CT, Narasimhan D, Jose D (2017) Awareness of Dental Trauma Management among School Teachers of Kannur, Kerala, India. J Clin Diagn Res 11(2): ZC08-ZC12.

2. Kaul R, Jain P, Saha N, Goswami S, Mukhopadhyay S, et al. (2017) Evaluation of knowledge, awareness, and attitude toward emergency dental trauma management among the schoolteachers of Kolkata. Indian J Dent Res 28(6): 595-603.

3. Kaul R, Jain P, Angrish P, Saha S, Patra TK, et al. (2016) Knowledge, Awareness and Attitude towards Emergency Management of KolkataAn Institutional Study. J Clin Diagn Res 10(7): ZC95-ZC101.

4. Parikh U, Shah K (2017) Assessment of knowledge of parents towards paediatric dental traumatic injuries International. International Journal of Applied Dental Sciences 3(4): 230-233.

5. Nissreen NM, Yahia EI, Amal HA (2016) Knowledge and attitude of Sudanese school health teachers regarding first aid management of dental trauma. Dent Oral Craniofac Research 2(2): 242-246.

6. Gupta S, Kumar Jindal S, Bansal M, Singla A (2011) Prevalence of traumatic dental injuries and role of incisal overjet and inadequate lip coverage as risk factors among 4-15 years old government schoolchildren in Baddi-Barotiwala Area, Himachal Pradesh, India. Med Oral Patol Oral Cir Bucal 16(7): e960-e965. 
7. Sushma SN, Alokkumar B, Anil V A (2016) Awareness regarding emergency dental trauma management among graduates of medical institutes in a city in India. Journal of Dental Research and Scientific Development 3(1): 6-12.

8. Raphael SL, Gregory PJ (1990) Parental awareness of the emergency management of avulsed teeth in children. Aust Dent J 35(2): 130-133.

9. Ain TS, Lingesha Telgi R, Sultan S, Tangade P, Ravishankar Telgi C, et al. (2016) Prevalence of Traumatic Dental Injuries to Anterior Teeth of 12-Year-Old School Children in Kashmir, India. Arch Trauma Res 5(1): e24596.

10. Azami Aghdash S, Ebadifard Azar F, Pournaghi Azar F, Rezapour A, Moradi Joo M, et al. (2015) Prevalence, etiology, and types of dental trauma in children and adolescents: systematic review and metaanalysis. Med J Islam Repub Iran 29(4): 234.
11. Jain A, Kulkarni P, Kumar S, Jain M (2017) Knowledge and Attitude of Parents towards Avulsed Permanent Tooth of their Children and its Emergency Management in Bhopal City. J Clin Diagn Res 11(5): ZC40ZC44.

12. Shoko Kinoshita-Kawano, Atsunori Sugibayashi, Yo Taguchi (2008) Lay knowledge and attitudes on the management of traumatically avulsed teeth and the use of mouthguards. Pediatric Dental Journal 18(2): 124130.

13. Nirwan M, Syed AA, Chaturvedi S, Goenka P, Sharma S (2016) Awareness in Primary School Teachers regarding Traumatic Dental Injuries in Children and Their Emergency Management: A Survey in South Jaipur. Int J Clin Pediatr Dent 9(1): 62-66.

\section{Your next submission with Juniper Publishers will reach you the below assets}

- Quality Editorial service

- Swift Peer Review

- Reprints availability

- E-prints Service

- Manuscript Podcast for convenient understanding

- Global attainment for your research

- Manuscript accessibility in different formats

( Pdf, E-pub, Full Text, Audio)

- Unceasing customer service

Track the below URL for one-step submission

https://juniperpublishers.com/online-submission.php 